\title{
Public goods experiments without confidentiality: a glimpse into fund-raising
}

\author{
James Andreoni ${ }^{\mathrm{a}, *}$, Ragan Petrie ${ }^{\mathrm{b}}$ \\ a Department of Economics, University of Wisconsin, 7434 Social Science Bldg., 1180 Observatory Drive, \\ Madison, WI 53706, USA \\ ${ }^{\mathrm{b}}$ Department of Economics, Andrew Young School of Policy Studies, Georgia State University, Atlanta, \\ GA 30303, USA
}

Received 22 July 2002; received in revised form 11 March 2003; accepted 19 March 2003

\begin{abstract}
Laboratory researchers in economics assiduously protect the confidentiality of subjects. Why? Presumably because they fear that the social consequences of identifying subjects and their choices would significantly alter the economic incentives of the game. But these may be the same social effects that institutions, like charitable fund-raising, are manipulating to help overcome free riding and to promote economic efficiency. We present an experiment that unmasks subjects in a systematic and controlled way. We show that, as intuition suggests, identifying subjects has significant effects. Surprisingly, we found that two supplemental conditions meant to mimic common fund-raising practices actually had the most dramatic influences on behavior.
\end{abstract}

(C) 2003 Elsevier B.V. All rights reserved.

Keywords: Public goods; Fund-raising; Economic efficiency

\section{Introduction}

Many public goods experiments have been conducted, all with great efforts to conceal the identities of the subjects. Why do researchers want to preserve confidentiality? Presumably we think the effects of identifying subjects and their generosity will interfere with the other economic incentives we are trying to test. That is, we think that the social effects are likely to be substantial.

* Corresponding author. Tel.: +1-608-263-3864.

E-mail address: andreoni@facstaff.wisc.edu (J. Andreoni). 
In real-world institutions, there also seems to be a belief that revealing the identity and generosity of givers is important. Charities often give their donors considerable opportunities to be identified, from publishing names of large givers to offering bumper-stickers and coffee mugs to donors. Perhaps the effects that experimenters are so assiduously removing from their studies are the factors that real providers of public goods are manipulating to overcome free riding and improve efficiency.

Whether and how identification affects giving, however, remains an open question. There is yet to be an analysis of giving to public goods in which the identity and generosity of donors is revealed. This paper presents a systematic attempt to introduce identification of subjects and their donations into an experiment on the provision of public goods. We do this in two stages. First we use a simple $2 \times 2$ design, bringing in identification of subjects by pictures and revelation of the subjects gifts. We unmask our subjects by presenting their digital photos to their partners. By using photos we assure that the method of identification is constant across all interactions. These treatments reveal that, relative to a baseline of neither information on giving nor identification of the givers, adding just information on generosity has no significant effect on giving, and neither does adding just the identity of the giver. However, a substantial impact comes from using both in combination. Information and identification together result in $59 \%$ more giving to the public good over the baseline of the typical public goods experiment.

The second part of our study is designed to bring in some reality from actual institutions on giving. Charitable institutions for fund-raising differ somewhat from our specialized setting. First, charities give people an option of remaining anonymous. The findings above suggest that this may be a bad idea. Is there some advantage to offering an option of anonymity that perhaps economists should consider adding to their models? We address this with a condition that also offers givers an option to remain anonymous.

Another way charities differ is by reporting gifts in categories. That is, if you give $\$ 60$ 99 to public radio you may get a coffee mug, but if you give \$100-200 you may get a tote bag. The program of the theatre lists donors by categories of 'patrons' and 'sponsors', for instance, based on their donations. These are likely intended to get people to 'round up' their donations to get into a higher category, so carefully constructed categories can boost donations. We see if this is true in our studies by also reporting contributions by categories.

We find that both the option of anonymity and category reporting have interesting effects. While virtually no subjects took the option to remain anonymous, this treatment raised the most dollars of giving of those in our study. Category reporting also had a significant effect of shifting gifts up to meet the lower bound of the higher category.

We conclude from our study that, first, the fears that social effects could interfere with the strict economic incentives are indeed well justified. Second, and more importantly, we provide evidence that in fact fund-raising institutions may be molded to take advantage of these effects in order to increase donations and improve efficiency. This result opens up new and important questions for research. If social effects have significant impacts, how are these being harnessed by economic institutions? Can we design new institutions for raising donations that can make the most of the interaction between social and economic motivations?

In the next section we provide some background into economic, sociological and psychological findings that predict that social interactions would be an important factor in 
experiments. Section 3 describes our experimental design. Section 4 presents the result of our basic experiment, and Section 5 presents the fund-raising-inspired studies. Section 6 is a conclusion.

\section{Background}

Before proceeding to our experiments, we review previous experimental work and outline the psychological foundation for social effects.

\subsection{What do we know from economics experiments?}

There are many hints from economic studies that social effects may be important. First, experiments have already identified the importance of culture (Roth et al., 1995), gender (Andreoni and Vesterlund, 2001; Eckel and Grossman, 1998, 2001), social capital (Carter and Castillo, 2002; Glaeser et al. 2000), and in-group effects (Polzer et al., 1999).

Second, knowing the actions of others in a social dilemma may affect cooperation. Information seems to have its strongest and most positive effect when it is available every time a contribution decision needs to be made (Sell and Wilson, 1991), but not when the information is available every few periods (Cason and Khan, 1999) or at the end of the game (Gachter et al., 1996). It also appears that the spread of the distribution may be important. Messick et al. (1983) found that high variance of other's decisions decreases cooperation.

Finally, identification seems to have a positive effect on cooperation. Identifying partners before playing a two-person game seems to consistently reduce social distance and increase cooperation. Visual identification of one's partner increased cooperation in Dictator and Prisoner's Dilemma games (Bohnet and Frey, 1999a,b; Fox and Guyer, 1978), and photographs of smiling partners induced more cooperation in trust games (Scharlemeann et al., 2001). There has been less work on identification with larger groups, but the existing evidence suggests that identification effects may not be so consistent. Brosig et al. (1999) found that one-time visual identification before playing a repeated public goods game had no effect on cooperation.

\subsection{Why do we expect information and identification to matter?}

The psychology literature suggests that cooperation may increase if people focus on the links between their actions and the actions of others and on the consequences of their behavior on fellow group members (Schwartz-Shea and Simmon, 1995) ${ }^{1}$. This means that, at a minimum, people need information on what others are doing. Individuals may use this

\footnotetext{
1 There is also strong evidence from the experimental economics literature (Brosig et al., 1999) and from the social psychology literature (Aquino and Reed, 1998; Kerr and Kaufman-Gilliland, 1994; Dawes, 1991; Orbell et al., 1988) that group discussion increases cooperation because it may enhance feelings of group identity and induce commitments to cooperate. However, since we wish to isolate the effects of identification and information, we do not allow for communication as it may confound these effects.
} 
information to engage in social comparison by using other's behavior as a reference point for decisions (Bazerman et al., 1992; Loewenstein et al., 1989; Berkowitz, 1972) ${ }^{2}$. That is, if people care how their contribution compares relative to some 'standard', then providing information on others' behavior may be important ${ }^{3}$.

Fund-raisers seem to anticipate some degree of social comparison by suggesting contribution levels, announcing what others have given, and listing donor's names and contribution amounts. Indeed, for those wishing to lead and influence others by 'setting a good example', the existence of social comparison is essential ${ }^{4}$.

The importance of prestige has also been established in the psychology literature (see Harbaugh, 1998a,b for a discussion of these literatures; see also Feldman, 1998; Keisling, 1994). For those seeking prestige, identifying contributors through publications, plaques, or announcements allows fund-raisers to provide prestige to whomever seeks it. By offering premium gifts that differ as to contribution amount, fund-raisers allow contributors to signal to others that they gave a certain amount. For those not seeking prestige but only some form of social approval, identification allows people an opportunity to demonstrate to others that they did their part.

If people care about prestige, then identification becomes essential. Only by identifying people, can prestige be conferred. Identification may also be important to social comparison. While the standard of comparison may be absolute (i.e. what is considered 'fair' by all), it may also depend on the identities of those who give. For example, women may care more how they compare with other women, or rich people may care how they compare with other rich people.

Pride and shame may be other underlying motivations. Shame is an emotion caused by a strong sense of guilt or disgrace. Psychologists describe shame as an emotion that makes us want to hide and hope it ends quickly (Broucek, 1991). Pride could be thought of at the other end of an axis, where we feel self-respect and self-value (Nathanson, 1987). An individual's actions and the knowledge that others know of his actions can evoke these emotions. The former emotion may be one to be avoided, and the other may be sought.

This suggests that pride or shame may be brought on by standing out from the others. People may feel shame for being the lowest contributor, and they may feel pride from being the highest. They may also feel shame for contributing less than the others or pride for contributing more. That is, pride and shame may amplify other social effects when identities are known.

The results from our experiments can help suggest which, if any, of these social effects should be developed in the future into a testable theoretical model.

2 Even more direct evidence of the soundness of social comparison theory comes from Cason and Mui (1997). They found that decisions in a team dictator game tended to be dominated by the more other-regarding member, even when those decisions followed an individual dictator game decision and each team member made a different choice.

3 Other examples of individuals' comparison of their actions with others from the economics literature include Di Tella et al. (2001) research on relative "happiness", Bordignon (1993) research on fairness and tax evasion, and Myles and Naylor (1996) research on social norms.

4 See Andreoni and Scholz (1998) for evidence from charitable giving. 


\section{Experiment}

\subsection{Experimental design}

Our experiments use a linear public goods game. The game is repeated, and subjects make their decisions on a computer network. There are five people in each group, and each subject is endowed with 20 tokens that could be spent on a private good (called the 'RED investment' in the experiment) or a public good (called the 'BLUE investment'). The private good pays the investor $\$ 0.02$ for each token invested, and the public good pays each group member $\$ 0.01$ for every token invested by any group member. So the marginal return to investing in the public good is 0.5 .

The basic $2 \times 2$ design incorporates information on the contributions of the group members and identification via digital photographs. The four treatments are outlined in Table 1 and are called Baseline, Information, Photos, and Information-and-Photos. In all treatments, subjects know total group contributions. The Baseline treatment is identical to standard linear public goods games. There is no information or identification. In the Information treatment, subjects know exactly what each group member contributes to the public good but does not see who is in their group. In the Photos treatment, subjects see photos of other group members but have no information on their individual contributions. In the Information-and-Photos treatment, subjects see photos and receive information, so they know exactly what each group member contributed.

We opted to use digital photographs to identify subjects to one another because such methods control the quality and nature of identification. Photographs capture and preserve the appearance and expression of the person but do not allow for communication, which might confound the effects of identification alone. Photos also eliminate any effects that could result from changing facial expressions with (non-audio) video presentations.

In treatments with subject identification, that is Photos and Information-and-Photos, the procedure is as follows. A digital photograph of each subject is taken at the beginning of the experiment. The photographs of each group member are displayed on the top of the computer screen at all times, so subjects know who is in their group.

When information is provided on each group member's contribution, the amount contributed is displayed on the top of the screen in descending order, with the highest contribution on the left and the lowest on right. When information and photos are displayed, the information on each group member's contribution is reported below his or her photograph. In this case, photographs are also arranged from the highest contribution to the public good to the lowest contribution.

The two 'fund-raising' sessions, Category-Reporting and Optional-Reporting, were named for their inspiration from real-world practices. The Category-Reporting treatment

\begin{tabular}{lll}
\hline & No photos & Photos \\
\hline No information & Baseline & Photos \\
Information & Information & Information-and-Photos \\
\hline
\end{tabular}


only differs from the Information-and-Photos treatment by its reporting method. Instead of reporting contributions exactly, contributions are reported by contribution categories ' 0 14 tokens' or ' $15-20$ tokens'. So, a contribution of two tokens or a contribution of 14 tokens would be reported as in the ' $0-14$ tokens' category.

In the Optional-Reporting treatment, there are two public goods instead of one, a broadcast public good and an anonymous public good. The two public goods are identical in terms of payoffs. Because payoffs are linear, the earnings of subjects are not affected by which public good they give to. However, the two public goods differ in terms of information. For the broadcast public good, subjects see photos and also know the exact contributions of the other group members. For the anonymous public good, only total group contributions are known. Therefore, individual contributions to the broadcast public good (called BLUE1 in the experiment) are known exactly, but individual contributions to the anonymous public good (called BLUE2 in the experiment) are not known exactly. This also means that photographs are rearranged based on contributions to the broadcast public good, not by contributions to the anonymous public good.

Subjects enter their decisions on a Decision Screen like that in Fig. 1, the Decision Screen used in the Optional-Reporting treatment. BLUE1 is the broadcast public good and



Fig. 1. Decision screen for Optional-Reporting treatment. 
BLUE2 is the anonymous public good ${ }^{5}$. The decision screens for the other five treatments can be easily derived from this one ${ }^{6}$.

Because we wish to explore social effects, we felt it was important to give those effects an opportunity to play out. In the information treatments, subjects do not learn of the contributions of other group members until the second round. Therefore, we opted for a repeated setting rather than a one-shot game. As such, we have an opportunity to observe the reaction of subjects to the actions of others.

\subsection{Experimental procedure}

Subjects were recruited from undergraduate classes in business and economics at the University of Wisconsin, Madison. Subjects are given an identification number, which they use to $\log$ onto the computer network to read the instructions and make decisions. They turn in the identification number at the end of the experiment to receive their payment. Subjects are paid in cash in private envelopes with their identification number written on the outside. Their names are never recorded.

There are 20 subjects in each session. They play with the same group of five people for eight rounds, then switch groups for another eight rounds, until they play with five different groups, each for eight rounds. Hence, subjects play 40 rounds in total, and each session takes about an hour and a half. The Photos, Information, Information-and-Photos, and Optional-Reporting treatments were conducted twice, so there are 40 subjects in total per treatment. The Baseline and Category-Reporting treatments were conducted only once, so there are 20 subjects in total per treatment. This gives us a total of 200 subjects participating in the experiments.

Subjects earned an average of \$26.11 (S.D. \$3.83). The average age of each subject was 20.22 years (S.D. 2.13 years), and $41 \%$ of subjects were women. Most subjects were sophomores and juniors and came from a variety of majors, including the liberal arts. A little over half were business majors (e.g. accounting, management, and marketing), and only $5 \%$ were economics majors.

\section{Results: do identity and reporting matter?}

In this section we describe the results from our basic $2 \times 2$ design.

\footnotetext{
5 Note that the photographs used in Fig. 1 are for illustration only and are not those of subjects from the experiments. The photographs of actual subjects were shown to other subjects in a particular session but, otherwise, are kept confidential. Subjects knew this prior to having their photos taken.

${ }^{6}$ For the Baseline treatment, there are no photos, no information listed below the photos, and no BLUE2 option. In the Photos treatment, there is no information and no BLUE2 option. For the Information treatment, there are no photos and there is no BLUE2 option. For the Information-and-Photos treatment, the only difference with Fig. 1 is that there is no BLUE2 option. For the Category-Reporting treatment, there is no BLUE2 option, and contributions are reported in categories, not exact amounts.
} 


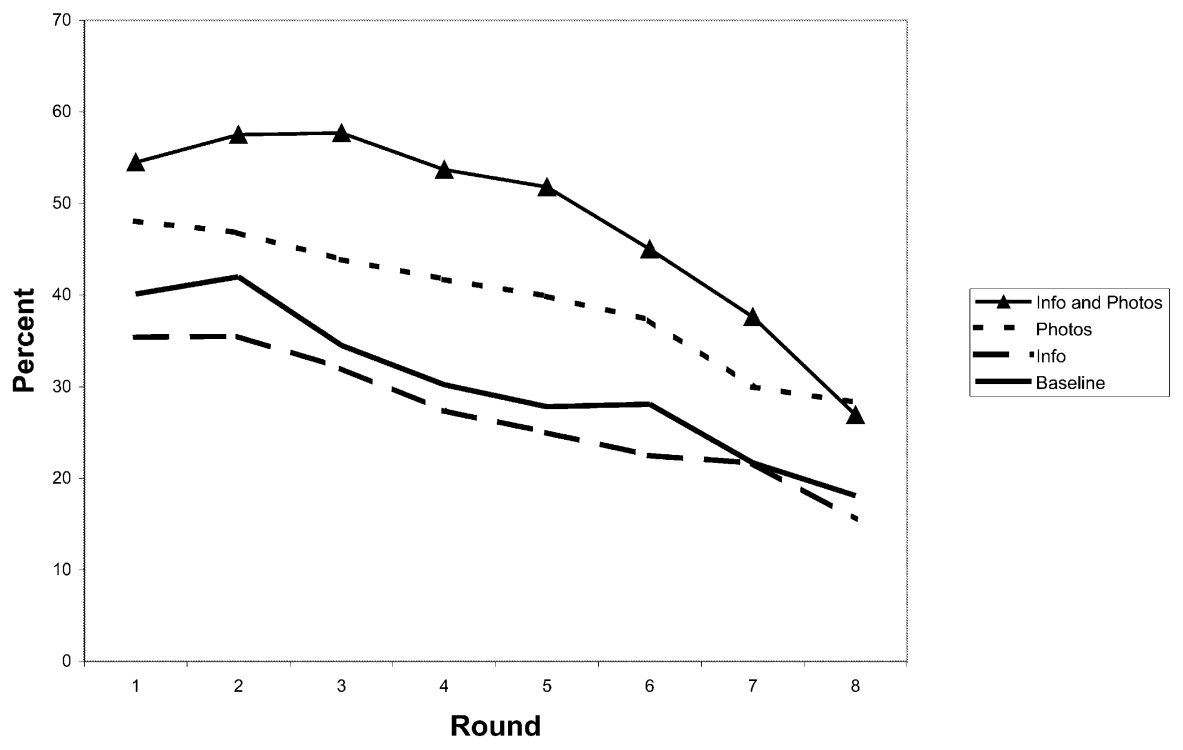

Fig. 2. Average percent of endowment contributed to the public good.

\subsection{Comparison to previous experiments}

How do our results compare with previous public goods experiments? The results from our $2 \times 2$ design show similar patterns to the stylized facts of repeated public goods games: contributions start high initially and decline over the period of repetition. This suggests diminishing gains to cooperation as the game nears completion. However, no treatment declines to complete free riding ${ }^{7}$. Fig. 2 shows the average percent contributed to the public good, combining all five 8-round sequences. Contributions start between 35\% in the Information treatment and 54\% in the Information-and-Photos treatment and decline to between 15 and $27 \%$, respectively.

The Baseline treatment compares well with previous experiments. The average contribution across all rounds, 30.3\%, is slightly lower than that of Andreoni (1988, 1995), 33.2\%, and Croson (1996), 35.7\%, and last rounds are higher, $18.1 \%$ in the Baseline compared with $11.6 \%$ in Andreoni and 10.6\% in Croson. Our treatment tends to suppress non-cooperative end-game behavior more than previous work $^{8}$.

How does behavior differ across treatments? From Fig. 2, we see that while information alone does not increase contributions relative to our Baseline treatment, identification

\footnotetext{
7 See Ledyard (1995) for a review of public goods experiments. Explanations for this "decay" seem to indicate that some cooperation in public goods games can be attributed to kindness, not solely due to subjects learning to free ride. This stylized fact of repeated public goods games could be due to kind subjects expressing frustration at the lack of reciprocation. See Andreoni (1995) and Houser and Kurzban (2002).

8 This may be due to the fact that our subjects play a series of finite games, rather than one.
} 
Table 2

Average contribution, zero tokens, all tokens (over all rounds)

\begin{tabular}{lllc}
\hline & $\begin{array}{l}\text { Average } \\
\text { percent } \\
\text { contributed }\end{array}$ & $\begin{array}{l}\text { Percent of } \\
\text { times } \\
\text { zero tokens } \\
\text { contributed }\end{array}$ & $\begin{array}{l}\text { Percent of } \\
\text { times } \\
\text { all tokens } \\
\text { contributed }\end{array}$ \\
\hline Baseline & 30.3 & 39.8 & 7.3 \\
Information & 26.9 & 46.3 & 9.8 \\
Photos & 39.5 & 22.4 & 11.9 \\
Information-and-Photos & 48.1 & 21.9 & 20.0 \\
\hline
\end{tabular}

does $^{9}$. Knowing who else is in the group increases contributions over all rounds. However, it is the combination of information and identification that increases contributions the most. Average contributions in the Information-and-Photos treatment lie strictly above average contributions in the Baseline treatment, the Information treatment, and the Photos treatment, except in the last round where all identification treatments are indistinguishable. This suggests that being able to link the action to the actor is an important mechanism to increase average contributions. We explore this in more detail below.

\subsection{Identity and reporting}

What is it about knowing who is in the group and what each contributed that increases contributions? From Table 2, we see that average contributions in the Baseline treatment are higher than in the Information treatment and lower than in the Photos treatment. None of these differences are significant. However, average contributions are significantly higher in Photos relative to Information. That is, identification is strictly better than information.

Yet, the average percent contributed to the public good over all rounds is significantly higher in the Information-and-Photos treatment compared with the Information treatment and the Photos treatment. Comparing the Photos treatment to the Information-and-Photos treatment, that is, when information is added to photos, average contributions increase by $21.7 \%$. And when comparing the Information treatment to the Information-and-Photos treatment, that is, when photos are added to information, average contributions increase by $78.8 \%^{10}$.

\footnotetext{
9 While Fig. 2 suggests that information alone is deleterious to contributions relative to the Baseline case, this difference is not statistically significant over all rounds nor across each round individually.

10 The $P$-value is 0.0423 comparing the Photos treatment and the Information-and-Photos treatment and is 0.0001 comparing the Information treatment to the Information-and-Photos treatment. We tested significance using the Wilcoxon rank sum test. The procedure was the following. Since subjects repeated the same decision 40 times, we averaged across individual contributions for all 40 rounds. So, we used $\bar{g}_{i}=\sum_{t=1}^{40} g_{i t} / 40$, the average contributed by individual $i$ over all 40 rounds. That means that for each comparison across treatments, we have 20 or 40 observations, one for each subject. If the treatment had two sessions, there would be 40 observations, otherwise there would be 20 observations.
} 
These results suggest two points. First, neither information nor identification in isolation has a signification effect. Second, in combination, they significantly increased giving.

What is causing average contributions to be higher? To explore this question, we look at extreme contributions. First, as seen in Table 2, the percent of times that zero tokens were contributed is almost indistinguishable below the line, when photos are used. This is significantly higher than the others, only when people cannot identify other group members. In the Baseline and Information treatments, roughly twice as many subjects free ride, compared with the other two treatments. Second, the percent of time that subjects contribute all of their tokens only increases when there is information and identification. In this case, subjects contribute all of their tokens at least $20 \%$ of the time; however, in the remaining treatments, subjects contribute no more than $12 \%$ of the time. Contributions of the full endowment are significantly higher in the Information-and-Photos treatments compared with all of the three other treatments, but there is no significant difference between these three treatments ${ }^{11}$.

This suggests that not only does the combination of identification and information increase contribution levels but, in fact, they serve different purposes. On average, identification alone and information alone are no different than the baseline case. However, by looking at the extremes, we see that photos reduce free riding, and the combination of photos and information encourage socially optimal behavior. Identification of other group members may serve to reduce social distance and encourage some level of social responsibility to the group ${ }^{12}$. Identification and information on individual actions allow people to serve as an example by providing verifiable information to others. If there are example setters, they can clearly signal what is the 'right' contribution and also get credit for it. We explore this possibility next.

\subsection{Leaders and laggards}

Next we ask whether there are indeed 'example setters' and, if so, how do they affect the contributions of others? While there are many ways of defining such leaders and laggards, we use a simple classification as a first step to explore these questions. We classify as a leader any subject who contributed 15 tokens or more in the first period in four out of five of the 8-round sequences. Likewise, we classify as a laggard any subject who contributed five tokens or less in the first period in four out of five of

\footnotetext{
11 For example, using a Wilcoxon rank sum test to test the percent of times all tokens are contributed in the comparison of Photos to Information yields a $P$-value of 0.4274 . Similar $P$-values hold for all other two-way comparisons of treatments above the line in Table 2 . However, the $P$-values comparing all treatments above the line to Information-and-Photos are significant. For example, the $P$-value comparing Photos to Information-andPhotos is 0.0119 .

12 The effect of photos is more nuanced than merely their presence or not. The physical appearance of the person in the photo is also important. For example, Andreoni and Petrie (2003) found strong gender differences in behavior and reactions and strong differences in reactions to attractive people. People were more cooperative with attractive people in the group, but only if group members were kept in the dark about who contributed what.
} 
Table 3

Distribution of leaders and laggards percent of subjects

\begin{tabular}{llllllrr}
\hline & Baseline & Information & Photos & $\begin{array}{l}\text { Information- } \\
\text { and-Photos }\end{array}$ & $\begin{array}{l}\text { Category- } \\
\text { Reporting }\end{array}$ & $\begin{array}{l}\text { Optional- } \\
\text { Reporting }\end{array}$ & $\begin{array}{c}\text { All } \\
\text { Leaders }\end{array}$ \\
\hline Laggards & 10.0 & 12.5 & 22.5 & 22.5 & 55.0 & 40.0 & 28.2 \\
\hline
\end{tabular}

the 8-round sequences. Anyone who was not classified as a leader or a laggard is called a follower ${ }^{13}$.

Using this classification, Table 3 shows the distribution of leaders and laggards. Looking just at the treatments in our $2 \times 2$ design, we see that there are about twice as many leaders in the Photos treatment and the Information-and-Photos treatment, compared with the Baseline treatment and the Information treatment. However, there is no significant difference between any of these four treatments ${ }^{14}$. This suggests that while the combination of information and identification has a significant effect on average contributions, it alone does not change the distribution of leaders, as we defined them. Table 3 also shows that there are significantly more laggards in the Baseline, Information, and Photos treatments. While the combination of information and identification alone did not increase the number of leaders, it does decrease the number of laggards.

How are leaders and laggards distributed within groups? Table 4 shows the distribution of groups within four classifications: groups with more leaders than laggards, groups with an equal number of leaders and laggards, groups with more laggards than leaders, and groups with no leaders or laggards. Two observations can be made from Table 4. First, there is a significantly higher proportion of groups with more leaders than laggards in treatments that combine information and identification. There are at least $67 \%$ more groups with more leaders than laggards in Information-and-Photos, compared with Baseline, Information, and Photos. Second, at the other extreme, there is a significantly higher proportion of groups with more laggards than leaders in treatments where actions cannot be tied to the actor. For example, $80 \%$ of groups in the Information treatment have more laggards than leaders.

How does the presence of leaders and laggards affect the behavior of followers? Table 5 shows the average contribution of followers within the group classification introduced in Table 4. As would be expected, the only treatments in which there is a significant effect on followers' behavior across all group classifications are those in which there is information on actions. So, in the Baseline and Photos treatments, where group members do not know what others are contributing, the number of leaders and laggards in the group has no significant effect on followers' behavior. However, when group members can verify others' behavior, there is a significantly positive effect of having more leaders than laggards in the group.

13 Note that this designation of leader, laggard or follower is completely arbitrary. However, similar results follow if we were to use slightly different cutoffs. A similar analysis of cutoffs is used in Gunnthorsdottir et al. (2001) for cooperative types.

${ }^{14}$ For example, a Chi-squared $\left(\chi^{2}\right)$ test for difference in distributions between the Baseline and Informationand-Photos treatments is insignificant $(P$-value $=0.238)$. 
Table 4

Distribution of groups by classification with leaders and laggards percent of groups

\begin{tabular}{lccccccr}
\hline & $\begin{array}{l}\text { Base- } \\
\text { line }\end{array}$ & $\begin{array}{l}\text { Infor- } \\
\text { mation }\end{array}$ & Photos & $\begin{array}{l}\text { Information- } \\
\text { and-Photos }\end{array}$ & $\begin{array}{l}\text { Category- } \\
\text { Reporting }\end{array}$ & $\begin{array}{l}\text { Optional- } \\
\text { Reporting }\end{array}$ & $\begin{array}{c}\text { All } \\
\text { More leaders }\end{array}$ \\
5.0 & 12.5 & 37.5 & 62.5 & 100.0 & 80.0 & 49.0 \\
Equal leaders/laggards & 40.0 & 5.0 & 15.0 & 12.5 & 0.0 & 7.5 & 12.0 \\
More laggards & 50.0 & 80.0 & 42.5 & 2.5 & 0.0 & 5.0 & 31.0 \\
No leaders/laggards & 5.0 & 2.5 & 5.0 & 22.5 & 0.0 & 7.5 & 8.0 \\
\hline
\end{tabular}

Leaders can bring up the contributions of followers, but laggards can bring them down. Indeed, the positive effect of leaders is strongest when the number of leaders outweighs the number of laggards in the group. In Information-and-Photos, followers contribute 50.3\% in groups with more leaders than laggards, compared with $33.9 \%$ in groups with more laggards than leaders. Contributions in groups with more leaders are also higher compared with groups with neither leaders nor laggards and to groups with an equal number of leaders and laggards.

Followers also contribute the most in groups with more leaders than laggards in the Information treatment. However, in Information, only $12.5 \%$ of groups have more leaders than laggards, whereas in Information-and-Photos this is $62.5 \%$. So, even though the intensity of the impact is large in Information, the overall impact of leadership is small. In fact, it is the impact of laggards that is the highest in this treatment.

These results suggest that leadership seems to work best when people can get credit for their actions, and laggardness is strongly present when actions cannot be tied to actors. Leaders seem to need a mechanism where they can send a clear signal of their actions. Whether the emergence of leaders is due to social comparison or prestige is not clear. However, some social comparison is at work with followers, as their contributions can vary significantly with the presence of leaders.

Laggards are a different story. They seem to flourish where they can hide behind noisy information or identification. There are more of them, and they appear to do the most damage when others know their presence but not their identity. In this case, having more of them in the group brings down the contributions of followers to its

Table 5

Contributions of followers average percent of endowment contributed to the public good

\begin{tabular}{llllllll}
\hline & $\begin{array}{l}\text { Base- } \\
\text { line }\end{array}$ & $\begin{array}{l}\text { Infor- } \\
\text { mation }\end{array}$ & Photos & $\begin{array}{l}\text { Information- } \\
\text { and-Photos }\end{array}$ & $\begin{array}{l}\text { Category- } \\
\text { Reporting }\end{array}$ & $\begin{array}{l}\text { Optional- } \\
\text { Reporting }\end{array}$ & All \\
\hline More leaders & 35.2 & 84.3 & 45.7 & 50.3 & 39.4 & 51.9 & 49.4 \\
Equal leaders/laggards & 29.0 & 35.4 & 36.5 & 24.7 & - & 41.0 & 30.8 \\
More laggards & 31.5 & 26.8 & 36.3 & 33.9 & - & 31.1 & 30.5 \\
No leaders/laggards & 51.7 & 7.0 & 43.0 & 36.6 & - & 37.3 & 36.7 \\
$P$-value & 0.124 & 0.000 & 0.218 & 0.000 & - & 0.003 & 0.000 \\
\hline
\end{tabular}

${ }^{a}$ Significance is tested across all four classifications using the Kruskal-Wallis test. In this case, an observation is the average behavior over the 7-round period after seeing the first round behavior of other group members. 
lowest level. Laggards, too, speak to the existence of social effects. Perhaps this is due to some sort of 'shaming' effect as there are far fewer of them when they can be identified.

\section{Fund-raising sessions: do charities know something we do not?}

We now describe the results of the fund-raising sessions. We begin with the option to remain anonymous, and then discuss reporting contributions by categories.

\subsection{The option of confidentiality}

It is clear that knowing who contributed what can significantly increase contributions, but why do fund-raisers give people the option of keeping their contributions confidential? Table 6 shows the average percent contributed in the Information-and-Photos treatment and the Optional-Reporting treatment, both anonymous and broadcast giving.

People contribute more when they are given the option of having their contribution announced. Over all rounds, people contributed 55.8\% in the Optional-Reporting treatment and $48.1 \%$ in the Information-and-Photos treatment. This is not significant at the conventional $10 \%$ level but is at the $12.9 \%$ level $(P$-value $=0.1284)$.

The more significant effect of having the option to announce one's contribution is in the percent of subjects that choose to set a good example more often. Table 3 shows that knowing who contributes what increases the number of leaders, albeit not significantly relative to the other treatments in our $2 \times 2$ design, but in Optional-Reporting the distribution of leaders does increase significantly. The percent of subjects that set a good example is $40 \%$, almost twice as many as when contribution reporting is required. Moreover, as in Information-and-Photos, Table 5 shows that having more leaders than laggards in a group significantly increases the contributions of followers in the OptionalReporting treatment.

Looking at whether people choose to announce or remain anonymous, of the total contribution to the two public goods, only $3.0 \%$ of endowments went to the anonymous public good while $52.8 \%$ went to the broadcast public good. This difference is, obviously, statistically significant. In fact, if people did not contribute to the broadcast public good, it was very unlikely that they contributed anonymously. Of all the contributions to the public

Table 6

Average percent contributed to the public good Information-and-Photos and Optional-Reporting treatments (combining all 8-round sequences)

\begin{tabular}{|c|c|c|c|c|c|c|c|c|c|}
\hline Round & 1 & 2 & 3 & 4 & 5 & 6 & 7 & 8 & All \\
\hline Broadcast public good & 59.9 & 63.4 & 59.3 & 56.7 & 54.0 & 51.4 & 45.5 & 32.1 & 52.8 \\
\hline Anonymous public good & 5.2 & 3.7 & 2.3 & 3.7 & 2.6 & 2.3 & 2.1 & 1.9 & 3.0 \\
\hline Total Optional-Reporting & 65.1 & 67.1 & 61.6 & 60.4 & 56.6 & 53.7 & 47.6 & 34.0 & 55.8 \\
\hline Information-and-Photos & 54.6 & 57.5 & 57.6 & 53.8 & 51.8 & 45.0 & 37.6 & 26.9 & 48.1 \\
\hline
\end{tabular}


good, $80.4 \%$ only went to the broadcast public good, $18.5 \%$ of contributions went to both public goods, and only $1.1 \%$ of contributions were strictly anonymous ${ }^{15}$.

These results suggest two things. First, given the option, people do not wish to remain anonymous. This was confirmed by answers to a questionnaire given to subjects after the experiment. A typical comment was, 'Never give to BLUE2 (the anonymous public good); people will assume you put them in RED (the private good)'.

Second, even though most people choose to have their contribution announced, having the option increases contributions relative to having announcements required, and it produces more leaders. This suggests that fund-raising institutions may be tapping into some behavioral anomalies by giving people the option of keeping their contribution anonymous, and this may raise total giving in two ways. Broadcasting contributions is clearly preferred, and having the choice leads to higher total contributions than in any other treatment. Also, it induces more people to set a good example, which others tend to follow.

\subsection{Reporting in categories}

Why do fund-raisers announce contributions in categories? We investigate this by comparing the Information-and-Photos treatment to the Category-Reporting treatment.

By chance, the categories we chose had little impact on the total amount given to the public good. Average contributions are $48.1 \%$ if reported exactly and $51.6 \%$ if reported in categories. Categories did produce more leaders (see Table 3), however, this is likely an artifact of our definition of leaders and the categories. In fact, there are so many leaders, that there are no groups without them (see Table 4) ${ }^{16}$.

While the categories we chose did not, in the end, change average contributions, they did have a dramatic effect on the distribution of those contributions. They do so in two ways. First, they shift contributions to the lower end of each of the two categories, ' $0-14$ tokens' and '15-20 tokens'. Fig. 3 shows this shift. When contributions are reported exactly, $21.9 \%$ of contributions were at zero tokens, and when contributions are reported by categories, this increases to $28.9 \%$. This difference across treatments is not significant, however, the difference is larger and is significant in the second category. Almost three times as many contributions were at 15 tokens under category reporting (31.8\%) compared with exact reporting $(12.3 \%)^{17}$. That is, more people are contributing at the lower end of

15 When someone contributed to both public goods, contributions to the anonymous public good were relatively small. In this case, the average contribution to the anonymous public good was $18 \%$ of the total endowment. Moreover, of the total amount contributed to both public goods, on average, $35 \%$ of that total was contributed to the anonymous public good. If someone contributed to both public goods, they did so in early rounds and then switched to contributing to the broadcast public good only. No subject gave anonymously over all 40 rounds.

16 Indeed, our cut-off for a "leader" coincides exactly with our second category in the Category-Reporting treatment. This confounds the effects of categories and leaders, and because of this, we do not discuss leadership in the Category-Reporting treatment.

17 The $P$-value for the difference across treatments in the percent of times zero tokens were contributed is 0.1218 , and for the percent of times 15 tokens were contributed, the $P$-value is 0.0021 . For zero tokens, we tested significance by averaging over the percent of times each subject contributed zero tokens across all 40 rounds. This means that for each comparison across treatments, we have 20 observations for Category and 40 observations for Information-and-Photos, one observation for each subject. 


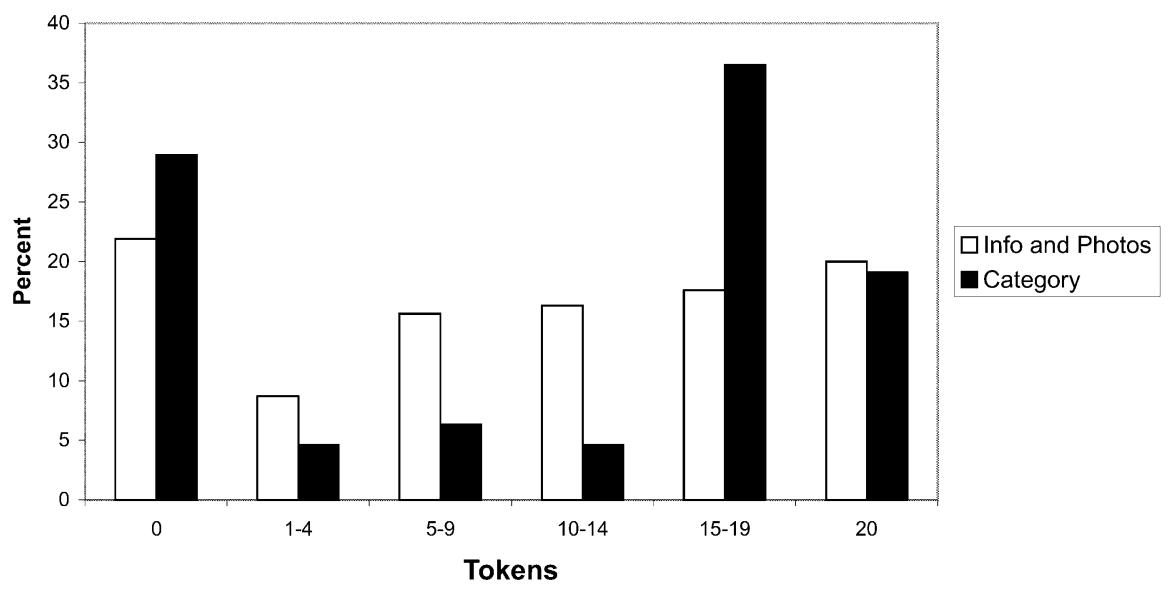

Fig. 3. Distribution of contributions to the public good, exact reporting and category reporting, categories $0-14$ or $15-20$

each contribution category in category reporting, and significantly so in the higher category.

Second, categories shift contributions to a higher level. When contributions are reported exactly, $37.6 \%$ of contributions are between 15 and 20 tokens, whereas when they are reported in categories this is $55.6 \%{ }^{18}$. This shift makes sense if there are social effects. Since a contribution of zero tokens or a contribution of 14 tokens would be reported identically, a subject seeking credit for a higher contribution would have to give 15 tokens. We see that significantly more do.

These results suggest that category reporting can be a powerful mechanism to affect contribution decisions. However, categories need to be carefully chosen to shift contributions in a desirable direction. Poorly chosen categories may reduce contributions or may have no effect on shifting contributions at all.

This also suggests that fund-raisers may tap into heterogeneity in preferences. If we look at the extremes of the distribution, categories have little effect. In both treatments, about $20 \%$ of contributions are of the full endowment, and about one quarter of contributions are of zero tokens. If everyone in the upper category was motivated by some sort of prestige, then we should have seen all contributions in the upper category at 15 tokens and none at 20 tokens. One needs only to contribute 15 tokens to get credit for being in the top category.

This suggests people may be different: some may be affected little by social effects and contribute zero tokens no matter what; some are more internally motivated and contribute all of their endowment no matter how the categories are set; and some are affected by social effects and are most swayed by contribution categories. This result parallels the intuition of actual fund-raisers, who argue that there are three groups of potential donors:

18 The $P$-value for this difference is 0.0103 . 
people who will never contribute, people who always contribute, and people who can be persuaded $^{19}$.

\section{Conclusion}

This paper set out to understand whether removing confidentiality affects giving in a series of public goods experiments. We systematically alter the identification of subjects and information on their contributions. By unmasking subjects, we allow for various social effects, like pride, shame, social comparison and prestige, to work. If identity and information matter, this raises the natural question: have fund-raising institutions been tailored to take advantage of these effects? To get a glimpse into fund-raising strategies, we also conducted two additional treatments. The first allows subjects the option of giving anonymously. The second reports contributions in categories. This allows us to observe whether these particular fund-raising practices may have special merit, and if they may be worth studying in more detail.

We found, first, that identity and information can matter. Knowing only the distribution of contributions, but not the identity of the givers, has no discernible effect. Knowing only the identity but not the individual contributions has a modest effect of increasing donations. However, knowing both who is in your group and what each is choosing can significantly increase giving. Identification tends to decrease free riding, and the combination of information and identification tends to increase contributions.

Looking more deeply, we discovered that some people consistently set a 'good example' by contributing large amounts in the first period. We found that the announcement structure has an important effect on the number of these leaders and their ability to lead. Surprisingly, leaders emerge most strongly when they can voluntarily report their contribution to the rest of the group. Moreover, as social comparison suggests, their role in the group is important as they appear to increase the contribution levels of others. Along with the leaders, we also uncovered laggards who consistently give small amounts in the first period. Laggards, we found, are cowardly. They emerge when information on actions and actors is noisy, and they cannot be easily identified. Even more insidious is that their presence appears to decrease the contributions of others. It seems the best way to deal with laggards is to make their actions and identities known.

Second, and perhaps surprisingly, we found that two popular fund-raising practices had significant impacts on behavior. For the option to remain anonymous we found that, while few chose to do so, having the option to contribute anonymously increased contributions to their highest level and produced the most leaders. That is, giving people the option to report their contributions results in more giving than required reporting. It would appear that something about empowering people with the choice to announce their contributions - even though it is a 'false' choice that no one would reject — might actually focus

\footnotetext{
19 This is from personal communication with a fund raiser who runs annual giving campaigns at the University of Wisconsin Foundation. Of course, those who always contribute could also be persuaded to give more.
} 
them more on being leaders and example setters. This suggests that indeed charities may be taking advantage of subtle behavioral effects in designing this feature of the giving institution.

Categories also have the potential to affect contributions by significantly shifting the distribution of contributions. This confirms Harbaugh (1998b) research, which incorporates a prestige motive to giving. People tend to contribute at the lower end of the contribution category, and some people give more to be in the higher category. Our results suggest that carefully constructing the reporting categories has the potential to significantly increase contributions.

The research we presented here suggests a broad set of new questions for economic researchers, both theorists and experimenters. The effects that economists factor out of their experiments and, to a large extent, out of theoretical models may be the very effects that fund-raising institutions may be using to help overcome free riding and promote efficiency. This suggests that there may be much to be gained by shifting our research toward understanding individual preferences, social effects, and the institutions designed to take advantage of them. Indeed, this research could be seen as a first step at collecting the kind of information that may be useful to inform a theoretical model of fund-raising practices.

\section{Acknowledgements}

We are grateful to Bart Lipman, Jean Paul Chavas, Marco Castillo, and two anonymous referees for helpful comments. We also thank the National Science Foundation for financial support.

\section{References}

Andreoni, J., 1988. Why free ride? Strategies and learning in public goods experiments. Journal of Public Economics 37, 291-304.

Andreoni, J., 1995. Cooperation in public goods experiments: kindness or confusion. American Economic Review 85, 891-904.

Andreoni, J., Petrie, R., 2003. Beauty, gender, and stereotypes: evidence from laboratory experiments. Working paper, University of Wisconsin, Madison.

Andreoni, J., Scholz, J.K., 1998. An econometric analysis of charitable giving with interdependent preferences. Economic Inquiry 36, 410-428.

Andreoni, J., Vesterlund, L., 2001. Which is the fair sex? Gender differences in altruism. Quarterly Journal of Economics 116 (1), 293-312.

Aquino, K., Reed, A., 1998. A social dilemma perspective on cooperative behavior in organizations: the effects of scarcity, communication, and unequal access on the use of a shared resource. Group and Organization Management 23 (4), 390-414.

Bazerman, M., Loewenstein, G., Blount-White, S., 1992. Reversals of preference in allocation decisions: judging an alternative versus choosing among alternatives. Administrative Science Quarterly 37 (2), 220-240.

Berkowitz, L., 1972. Social norms, feelings, and other factors affecting helping and altruism. In: Berkowitz, L. (Ed.), Advances in Experimental Social Psychology. Academic Press, New York.

Bohnet, I., Frey, B., 1999a. The sound of silence in prisoner's dilemma and dictator games. Journal of Economic Behavior and Organization 38, 43-57.

Bohnet, I., Frey, B., 1999b. Social distance and other-regarding behavior in dictator games: comment. American Economic Review 89 (1), 335-339. 
Bordignon, M., 1993. A fairness approach to income tax evasion. Journal of Public Economics 52 (3), 345 - 362. Brosig, J., Axel, O., Joachim, W., 1999. Why does communication enhance cooperation? Working paper. Broucek, F.J., 1991. Shame and the Self. The Guilford Press, New York.

Carter, M., Castillo, M., 2002. Trust and altruism: an experimental approach to social capital. Working paper, University of Wisconsin, Madison.

Cason, T., Mui, V.-L., 1997. A laboratory study of group polarisation in the team dictator game. The Economic Journal 107, 1465-1483.

Cason, T., Khan, F., 1999. A laboratory study of voluntary public goods provision with imperfect monitoring and communication. Journal of Development Economics 58, 533-552.

Croson, R., 1996. Partners and strangers revisited. Economics Letters 53, 25-32.

Dawes, R., 1991. Social dilemmas, economic self-interest, and evolutionary theory. In: Brown, R., Smith, J.E.K. (Eds.), Frontiers of Mathematical Psychology: Essays in Honor of Clyde Coombs. Springer, New York.

Di Tella, R., MacCulloch, R., Oswald, A., 2001. Preferences over inflation and unemployment: evidence from surveys of happiness. American Economic Review 91 (1), 335-341.

Eckel, C., Grossman, P., 1998. Are women less selfish than men? Evidence from dictator experiments. Economic Journal 108 (448), 726-735.

Eckel, C., Grossman, P., 2001. Chivalry and solidarity in ultimatum games. Economic Inquiry 39 (2), $171-188$.

Feldman, R.S., 1998. Social Psychology, second ed Prentice Hall, Upper Saddle River, NJ.

Fox, J., Guyer, M., 1978. Public' choice and cooperation in $n$-person prisoner's dilemma. Journal of Conflict Resolution 22 (3), 469-481.

Gachter, S., Fehr, E., Kment, C., 1996. Does Social Exchange Increase Voluntary Cooperation? Kyklos 49 (4), $541-554$.

Glaeser, E., Laibson, D.I., Scheinkman, J.A., Soutter, C.L., 2000. Measuring trust. Quarterly Journal of Economics 115 (3), 811-846.

Gunnthorsdottir, A., Houser, D., McCabe, K., Ameden, H., 2001. Dispositions, history and contributions in public goods experiments. Working paper, Australian Graduate School of Management, Australia.

Harbaugh, W., 1998a. The prestige motive for making charitable transfers. American Economic Review 88 (2), $277-282$.

Harbaugh, W., 1998b. What do donations buy? A model of philanthropy based on prestige and warm glow. Journal of Public Economics 67, 269-284.

Houser, D., Kurzban, R., 2002. Revisiting kindness and confusion in public goods experiments. American Economic Review 92, 1062-1069.

Keisling, L.L., 1994. Moral sentiments and conspicuous donations: social approval and altruism in private charity. Working paper, Department of Economics, College of William and Mary, Williamsburg, VA.

Kerr, N., Kaufman-Gilliland, C., 1994. Communication, commitment, and cooperation in social dilemmas. Journal of Personality and Social Psychology 66 (3), 513-529.

Ledyard, J.O., 1995. Public goods: a survey of experimental research. In: Kagel, J.H., Roth, A.E. (Eds.), The Handbook of Experimental Economics. Princeton University Press, Princeton, NJ.

Loewenstein, G., Thompson, L., Bazerman, M., 1989. Social utility and decision making in interpersonal contexts. Journal of Personality and Social Psychology 57 (3), 426-441.

Messick, D., Wilke, H., Brewer, M., Kramer, R., 1983. Individual adaptations and structural change as solutions to social dilemmas. Journal of Personality and Social Psychology 44 (2), 294-309.

Myles, G., Naylor, R., 1996. A model of tax evasion with group conformity and social customs. European Journal of Political Economy 12 (1), 49-66.

Nathanson, D., 1987. The shame/pride axis. In: Lewis, H.B. (Ed.), The Role of Shame in Symptom Formation. Erlbaum, Hillsdale, NJ.

Orbell, J., van de Kragt, A., Dawes, R., 1988. Explaining discussion-induced cooperation. Journal of Personality and Social Psychology 54 (5), 811-819.

Polzer, J., Stewart, K., Simmons, J., 1999. A social categorization explanation for framing effects in nested social dilemmas. Organizational Behavior and Human Decision Processes 79 (2), 154-178.

Roth, A., Prasnikar, V., Okuno-Fujiwara, M., Zamir, S., 1995. Bargaining and market behavior in Jerusalem, Ljubljana, Pittsburgh, and Tokyo: an experimental study. American Economic Review 81 (5), $1068-1095$. 
Scharlemeann, J., Eckel, C.C., Kacelnik, A., Wilson, R.K., 2001. The value of a smile: game theory with a human face. Journal of Economic Psychology 22 (5), 617-640.

Schwartz-Shea, P., Simmon, R.T., 1995. Social dilemmas and perceptions: experiments on framing and inconsequentiality. In: Schroeder, D. (Ed.), Social Dilemmas: Perspectives on Individuals and Groups. Praeger, Westport, CT.

Sell, J., Wilson, R., 1991. Levels of information and contributions to public goods. Social Forces 70 (1), $107-124$. 